\title{
Headaches and migraine in colour retouchers
}

\author{
P. J. TAYLOR, S. J. POCOCK, S. A. HALL, and W. E. WATERS \\ TUC Centenary Institute of Occupational Health, London School of Hygiene and \\ Tropical Medicine, London, W.C.1 and the Medical Research Council's Epidemiology \\ Unit (South Wales), Cardiff
}

\begin{abstract}
Taylor, P. J., Pocock, S. J., Hall, S. A., and Waters, W. E. (1970). Brit. J. industr. Med., 27, 364-367. Headaches and migraine in colour retouchers. A method is described for the study of headaches and migraine in occupational groups. The prevalence of headaches was studied in 158 colour retouchers and 115 page planners in the photogravure industry by means of a selfadministered questionnaire and a clinical interview. There was no difference in types of headaches although the first group used the word 'migraine' more frequently than the second. Questionnaire findings were very similar to those obtained from a sample of 727 males in South Wales, although infrequent headaches were more common in both printing groups.
\end{abstract}

When an occupational factor is suspected as one of the possible causes of a disease it is usual to enquire whether a significant association exists between the two. If the diagnosis can be confirmed by objective tests, prevalence rates can be compared with those in the general population or in suitable control groups. If the condition is one for which no such tests are established, and when there is also a problem of definition, the situation becomes more complex. Migraine has no known morbid anatomy (Walshe, 1969) and present definitions (e.g., World Federation of Neurology's Research Group on Migraine and Headache, 1969) are not sufficiently precise for epidemiological purposes. There is little information on the prevalence of migraine in the community although it is generally considered to be more frequent among women. Estimates of its prevalence in men have varied from $1 \%$ (Clark, Elsom, Montgomery, and Ipsen, 1969) and 5\% (Childs and Sweetnam, 1961) to nearly $16 \%$ (Fitz-Hugh, 1940). This paper reports on the use of a headache questionnaire developed at the Medical Research Council Epidemiology Unit (South Wales) and clinical interviews in an investigation into the prevalence of headache and migraine in photogravure colour retouchers.

These skilled craftsmen do close and fine work touching up photographic negatives in front of fluorescent screens. For some years it has been thought, within the printing industry, that these men suffered unduly from migraine. This impression was originally based upon the number seeking medical attention in one large firm, and was strengthened by the results of a self-administered questionnaire arranged by the union two years before this survey in which all retouchers were asked a direct question, 'Do you suffer from migraine?' This paper presents data on the prevalence of headaches, and the symptoms usually considered to be associated with migraine, among colour retouchers and two control groups.

\section{Methods}

The survey was undertaken in two similar printing works in a town near London. The full support of both the managements and the union was obtained. At the time of the survey 159 colour retouchers were employed. Photographic page planners from both printing works were chosen as a control group (123 men); they belong to the same craft union as retouchers and work on fluorescent benches whilst planning the layout of the page. They had not complained of excessive migraine and had not been included in any previous enquiries. A second, and much larger, group from outside the printing industry was also used. This consisted of 727 men aged from 21 to 74 years taken from a random sample of 2,000 subjects selected 
from electoral rolls in the Pontypridd area of South Wales. These formed part of a large-scale study undertaken by one of us (W.E.W.) into the epidemiology of headaches.

The survey amongst retouchers and planners was in two stages - self administration of the "headache questionnaire' followed by a clinical interview. Only the questionnaire was used on the Pontypridd control group.

The questionnaire consisted of 17 items about the frequency, severity and nature of headaches and included three special questions about the common accompaniments of migraine, namely: (1) some warning before the headache, (2) associated nausea or vomiting, and (3) pain on one side of the head only. The word 'migraine' is nowhere used in the form. After completing the form the retouchers and planners were interviewed and invited to amplify any points about their headaches. They were then asked whether they considered that their headaches were related to their work, whether they considered that they suffered from migraine (and if so who had made the diagnosis) and whether they had any other medical disability. Brief ophthalmoscopic examinations of the optic discs were made to exclude signs of raised intracranial pressure or hypertensive retinopathy, but none was found. It was not possible to see retouchers and planners in random order but the groups were mixed as far as practicable. In most cases the actual occupation was not known at the time of the interview.

\section{Results}

\section{Response rate}

A response rate of $99 \%$ to the questionnaire was achieved from retouchers and of $93 \%$ from planners; the rate in Pontypridd was $94 \%$. Lower rates were achieved for the interviews with the printers, $83 \%$ of retouchers and $61 \%$ of planners. Most of those not interviewed were away from the works on the days of the visits, but a few refused on the grounds that there was no need to see a doctor as they were not troubled by headaches.

As a preliminary analysis of the results showed no significant or consistent differences between retouchers and between planners in the two printing works, the figures from both works have been combined. The age structure and response rates of the groups studied are shown in Table 1.
As it is well recognized that headaches and migraine are less common in older persons (Waters, 1970), all findings from both the questionnaire and the interview have been considered in three age groups, 20-34, 35-54 and 55 years or more. The results have been age-standardized using the age distribution of the population of all retouchers and are expressed as a percentage of positive findings.

\section{Replies to questionnaire}

The first question asked 'Have you had a headache within the past year?' and the next enquired whether these were usually mild or severe or both. In the analysis, those with both types of headache were counted as having severe ones. A further question enquired about the frequency of headaches and offered six alternatives, ranging from 'about once a year' to 'several times a week'. There were also the three special questions about the common accompaniments of migraine (an aura, nausea, unilateral headache). The numbers and age-standardized percentages of positive replies to these questions were calculated for each of the three groups (Table 2).

Both printing groups had a significant excess of headaches of some sort compared with the Pontypridd men, but the difference for severe headaches was slight and not statistically significant. Frequent headaches were equally common in all three groups and the excess of headaches amongst the printers was confined to those occurring at infrequent intervals of once a month or less.

There were no significant differences between retouchers and planners in replies about headaches, and indeed severe ones were slightly more common amongst the planners. No significant difference was found between any of the three groups in the number of positive replies to the special questions.

The two groups of printers were also asked whether headaches tended to come on any particular day of the week. The great majority $(90 \%)$ replied that they came on any day, and the remainder were equally divided between weekdays and weekends; there was no difference in this between retouchers and planners.

TABLE 1

Response in Retouchers and Planners by Age Group

\begin{tabular}{|c|c|c|c|c|c|c|}
\hline \multirow{2}{*}{ Age group } & \multicolumn{3}{|c|}{ Colour retouchers } & \multicolumn{3}{|c|}{ Page planners } \\
\hline & \multirow{2}{*}{$\begin{array}{c}\text { Population } \\
52 \\
86 \\
21\end{array}$} & \multirow{2}{*}{$\begin{array}{c}\text { Questionnaire } \\
51 \\
86 \\
21\end{array}$} & \multirow{2}{*}{$\begin{array}{c}\text { Interview } \\
42 \\
71 \\
19\end{array}$} & \multirow{2}{*}{$\begin{array}{c}\text { Population } \\
39 \\
55 \\
29\end{array}$} & \multirow{2}{*}{$\begin{array}{c}\text { Questionnaire } \\
38 \\
49 \\
28\end{array}$} & \multirow{2}{*}{$\begin{array}{c}\text { Interview } \\
26 \\
31 \\
18\end{array}$} \\
\hline $\begin{array}{l}20-34 \quad \ldots \\
35-54 \\
55 \text { and ov }\end{array}$ & & & & & & \\
\hline Total .. & 159 & 158 & 132 & 123 & 115 & 75 \\
\hline
\end{tabular}


TABLE 2

RePlies to HeADAChe QUeSTIONNAIRE

(Results shown as numbers of men and as age-standardized percentages)

\begin{tabular}{|c|c|c|c|c|c|c|}
\hline \multirow{2}{*}{ Answers } & \multicolumn{2}{|c|}{$\begin{array}{c}\text { Retouchers } \\
(\mathrm{n}=158)\end{array}$} & \multicolumn{2}{|c|}{$\begin{array}{c}\text { Planners } \\
(\mathrm{n}=115)\end{array}$} & \multicolumn{2}{|c|}{$\begin{array}{l}\text { Pontypridd } \\
(\mathrm{n}=727)\end{array}$} \\
\hline & No. & $\begin{array}{c}A S^{2} \\
\%\end{array}$ & No. & $\underset{\%}{A S^{2}}$ & No. & $\underset{\%}{A S^{2}}$ \\
\hline $\begin{array}{l}\text { No headaches in past year .. } \\
\text { Severe headaches ... } \\
\text { Headaches once a month or less ... } \\
\text { Headaches more than once a month } \\
\text { All } 3 \text { special questions + ve } \\
\text { Two or more special questions + . . } \\
\text { One or more special questions + ve.. }\end{array}$ & $\begin{array}{l}36 \\
57 \\
88 \\
34 \\
10 \\
32 \\
72\end{array}$ & $\begin{array}{l}23^{1} \\
36 \\
55^{1} \\
22 \\
6 \\
20 \\
46\end{array}$ & $\begin{array}{r}24 \\
42 \\
66 \\
25 \\
4 \\
21 \\
55\end{array}$ & $\begin{array}{l}20^{1} \\
40 \\
57^{1} \\
23 \\
3 \\
19 \\
48\end{array}$ & $\begin{array}{r}246 \\
221 \\
325 \\
156 \\
38 \\
131 \\
297\end{array}$ & $\begin{array}{r}31 \\
32 \\
47 \\
22 \\
5 \\
19 \\
42\end{array}$ \\
\hline
\end{tabular}

${ }^{1}$ Difference from Pontypridd men significant at $5 \%$ level.

${ }^{2} \mathrm{AS} \equiv$ Age-standardized.

The replies of those who were subsequently interviewed were compared with those who were not. This showed that there was no difference between retouchers interviewed and the rest in terms of prevalence of headaches, but that planners not interviewed had a slightly lower prevalence of headaches.

\section{Replies at the interviews}

In contrast to the findings from the questionnaire, one marked difference between retouchers and planners emerged from the direct question, 'Do you suffer from migraine?' Twenty-eight retouchers and six planners claimed to have migraine, although similar proportions of each group thought that their headaches were related to work (Table 3).

The other questions at the interview concerning any recent change in headaches, age of onset of migraine, and who had made the diagnosis of migraine gave very similar results. It is worth noting that just less than half of those claiming to

TABLE 3

\section{REPLIES TO INTERVIEW}

(Results shown as numbers of men and as age-standardized percentages)

\begin{tabular}{c|c|c|c|c}
\hline \multirow{2}{*}{ Answers } & \multicolumn{2}{|c|}{$\begin{array}{c}\text { Retouchers } \\
(\mathrm{n}=132)\end{array}$} & \multicolumn{2}{|c}{$\begin{array}{c}\text { Planners } \\
(\mathrm{n}=75)\end{array}$} \\
\cline { 2 - 6 } & No. & $\begin{array}{c}A S^{2} \\
\%\end{array}$ & No. & $\begin{array}{c}A S^{2} \\
\%\end{array}$ \\
\hline Claim migraine $\ldots$ & 28 & $21^{1}$ & 6 & $\begin{array}{c}6^{1} \\
45\end{array}$ \\
\hline
\end{tabular}

${ }^{1}$ More retouchers claim migraine than planners $(P<0.01)$ ${ }^{2} \mathrm{AS} \equiv$ Age-standardized. have migraine in each group had been given the diagnosis by a doctor.

\section{Discussion}

One of the results of the clinical interview of the two printing groups appears to confirm the impression that the retouchers had a higher prevalence of migraine than the planners. This was in reply to a direct question about migraine. However, even doctors disagree on what proportion of headaches should be included in this term (Wolff, 1963) so it is obviously unreasonable to accept the diagnosis from the sufferers themselves, especially as less than half had been given the diagnosis by a doctor. Furthermore, the attention of all retouchers, but not planners, had been drawn to the subject of migraine by the earlier questionnaire. Thus in this respect we were dealing with one group that might be biased and one that probably was not.

The headache questionnaire used in the survey deliberately eschews the problem of defining migraine. It measures the prevalence of headaches, their severity and the prevalence of headaches with some form of aura, unilateral pain, and headaches accompanied by nausea. These prevalences are related to age (Waters, 1970) and therefore all results given in this paper have been age-standardized. The prevalences in the three groups are remarkably similar except that significantly more printers claimed to have headaches once a month or less. While we have no evidence to explain this difference, there is a widely held belief that headaches (and migraine) are more common in the upper social classes. Skilled craftsmen such as retouchers and planners belong to the Registrar General's social class III, and the high wages and traditional social status of craftsmen in this industry tend to result in 
a standard of living resembling social class II (Sadler, 1970). Moreover these men are carefully selected as apprentices for an interest and aptitude in artistic work. Males in the Pontypridd survey, on the other hand, would be more representative of the population as a whole.

There is no evidence from the replies to the questionnaire that the prevalence of severe headaches, or the features of migraine, differ significantly in the three groups studied. A comparative assessment of symptoms is always difficult but we believe that the replies to a standard questionnaire as described here are likely to be less biased than those to one in which the word migraine is used. This is all too often used like Lewis Carroll's Humpty Dumpty in Through the Looking Glass who said, 'When I use a word it means just what I choose it to mean - neither more nor less'.

We should like to thank all those whose help and co-operation made this survey possible and in particular the nursing sisters at both factories. We are grateful also to our colleagues for critical advice in the preparation of this paper.

\section{References}

Childs, A. J., and Sweetnam, M. T. (1961). A study of 104 cases of migraine. Brit. J. industr. Med., 18, 234-236.

Clark, T. W., Elsom, K. O., Montgomery, E. H., and Ipsen, J. (1969) Clinical and biological observations on working men. Arch. environm. Hlth, 19, 700-711.

Fitz-Hugh, T. (1940). Precordial migraine: an important form of 'angina innocens'. New int. Clin., n.s. 3, 1, 141-147.

Sadler, P. (1970). Sociological aspects of skill. Brit. J. industr. Relat., 8, 22-31.

Walshe, F. M. R. (1969). The enigma of migraine. Hemicrania, 1, no. 1 , pp. 5-8.

Waters, W. E. (1970). Community studies of the prevalence of headache. Headache, 9, 178-186.

Wolff, H. G. (1963). Headache and Other Head Pain, 2nd ed. Oxford University Press, New York.

World Federation of Neurology's Research Group on Migraine and Headache (1969). Hemicrania, 1, no. 1, pp. 3-4.

\section{Headache questionnaire}

1. Have you had a headache within the past year? YES/NO. If NO, have you ever had a headache in your life? YES/NO.

(If you have had a headache during the past year, please answer all the questions below for your headaches during the past year only. We do not want details of any headaches that happened more than one year ago, unless specially mentioned.)

2. Are your headaches usually mild or severe, or do you get both mild and severe headaches? Mild/Severe/ Both. If you get both mild and severe headaches, are they different kinds of headache, that is can you clearly distinguish between them? YES/NO.

(If you get both severe and mild headaches, please answer all the questions for your severe headaches only.)
3. Which one of these statements is nearest the truth for you? My headaches are very mild/My headaches are mild/My headaches are not usually severe/My headaches are quite severe/ My headaches are very severe/My headaches are terribly severe/My headaches are almost unbearable.

4. Which of these statements is nearest the truth for you? I hardly notice my headaches at all/My headaches rarely inconvenience me/My headaches sometimes distract me from what I am doing/ Sometimes I am unable to continue my normal activities because of my headaches/My headaches sometimes interfere a lot with what I am doing/I can hardly do anything when I have a headache/I am absolutely fit for nothing when I have a headache.

5. How long do your headaches usually last?

6. (a) When you have a headache, do you usually have to lie down/rest/take things easy? If you do, for how long is this usually?

(b) Have you missed work during the past year because of a headache? YES/NO. If YES, for how many days?

7. Do you get a headache about once a year/several times a year/ about once a month/several times a month/about once a week/several times a week? (Include all headaches, mild and severe.)

8. Are your headaches throbbing or thumping? Never/Sometimes/Usually/Always.

9. Where do you usually feel the headaches? Temples/ Forehead/Back of head/Top of head/All one side/All over the head. If elsewhere, where?

10. Are your headaches on one side only? Never/Sometimes/Usually/Always.

11. Before you get a headache do you know that one is coming? YES/NO. If you do, please describe briefly what you notice.

12. When you have a headache do you notice any changes in your sight? YES/NO. If YES, please describe briefly what you notice.

13. When you have a headache do you lose your appetite/ feel dizzy/feel sleepy/hear ringing in your ears/find that light hurts your eyes/notice tingling or any strange feeling in any part of your body?

14. When you have a headache do you ever feel sick/ usually feel sick/ever vomit/usually vomit/always vomit?

15. Have you ever seen a doctor about the headaches? YES/NO. If YES, have you seen a doctor about the headaches during the past year? YES/NO.

16. Over the years have your headaches become more frequent/less frequent/or have you noticed no change?

17. Over the years have your headaches become more painful/less painful/or have you noticed no change?

THREE EXTRA QUESTIONS FOR PRINTERS' SURVEY ONLY

18. Do your headaches tend to occur on any particular day of the week? YES/NO. If YES, please specify.

19. Do your headaches tend to start at a particular time of day? YES/NO. If YES, please specify.

20. When did you last have a headache? .......Month .......Year.

Received for publication March 23, 1970. 